\title{
REFLEXÕES SOBRE OS SUPER-HERÓIS NA EDUCAÇÃO E SUAS POTENCIALIDADES
}

Sandro Luiz, Modesto*

\begin{abstract}
RESUMO: Os super-heróis, tão presentes na vida de crianças e adolescentes, têm potencialidades para contribuir no ensino/aprendizado na educação básica. O mito do super-herói e sua influência no inconsciente coletivo, sua dimensão axiológica (ideológica) e sua moralidade fornecem bases para pensar no poder dos super-heróis na educação. Assim, o potencial dos super-heróis é uma realidade a ser explorada na educação de crianças e adolescentes.
\end{abstract}

Palavras-chave: super-herói; educação; inconsciente coletivo; axiologia (ideologia); moralidade.

\section{REFLECTIONS ON SUPERHEROES IN EDUCATION AND THEIR POTENTIAL}

\begin{abstract}
Superheroes, so present in the lives of children and adolescents, have the potential to contribute to teaching/learning in basic education. The superhero myth and its influence on the collective unconscious, its axiological (ideological) dimension and its morality, provide a basis for thinking on the power of superheroes in education. Thus. the potential of superheroes is a reality to be explored in the education of children and adolescents.
\end{abstract}

Keywords: superhero; collective; unconscious; education; axiology (ideology); morality.

\section{Introdução}

Os super-heróis fazem parte da vida de muitas crianças e adolescentes. Inicialmente, se tornaram populares nas histórias em quadrinhos e depois aumentaram com o crescimento do gênero nos cinemas, na TV e nos serviços de streaming, com as séries animadas ou live action e o investimento da indústria cultural nos games, brinquedos e outros produtos para o público infanto-juvenil.

Essas popularizações entre os estudantes da educação básica, a moralidade, o inconsciente coletivo e a ideologia contribuem para que os super-heróis se tornem instrumento didático-pedagógico. Há muitas possibilidades a serem exploradas e já existem professores de diversas disciplinas que incluem os super-heróis no processo de ensino-aprendizagem.

* Mestre em Filosofia - UFES (Universidade Federal do Espírito Santo). Professor de Filosofia no ensino fundamental e médio. Email: sandrovisky07@gmail.com ORCID: https://orcid.org/0000-0002-4420-3454 
O objetivo deste artigo é investigar as potencialidades didático-pedagógicas dos super-heróis. Se super-heróis são populares entre os jovens estudantes e se outros aspectos dos super-heróis apresentam aspectos da realidade, há o potencial de levar o aluno a pensar esse objeto que reproduz ou problematiza a realidade, atingindo o objetivo do professor(a) ao colocar os super-heróis em contato com o pensar do estudante.

\section{O SUPER-HERÓI: INCONSCIENTE COLETIVO, IDEOLOGIA (AXIOLOGIA) E MORALIDADE}

Nildo Viana (2003) diferencia herói de super-herói. O herói é alguém com habilidades especiais e com grande coragem, que pode ser alguém da vida real e o super-herói é alguém com superpoderes, um personagem fictício inicialmente dos gêneros de quadrinhos de superaventuras.

O herói como força mítica existe desde a antiguidade e representa o ser humano e suas superações. "O herói [...] é o homem ou mulher que conseguiu vencer suas limitações históricas pessoais e locais e alcançou formas normalmente válidas, humanas. As visões, ideias e inspirações dessas pessoas vêm diretamente das fontes primárias da vida e do pensamento humano" (CAMPBELL, 1995, p.13).

O herói na narrativa mítica é sujeito de transcendência que, com suas virtudes, como coragem e determinação, passa por veredas que o faz sofrer, mas que o transforma. O herói do mito obtém um triunfo macrocósmico, histórico-universais, como os heróis universais Maomé, Jesus, Gautama Buda e mesmo os heróis tribais ou locais, tais como o imperador Huang-ti, Moisés ou o asteca Tezcatlipoca (CAMPBELL, p. 22,1995) que beneficiam a comunidade local ou a própria humanidade.

O mito do herói chega até nós pelos arquétipos do inconsciente coletivo. Sem negar o inconsciente individual de Freud, C.G. Jung afirma o inconsciente coletivo como base de repouso do inconsciente individual, uma camada mais profunda de caráter universal que tem como conteúdo os arquétipos (JUNG, p. 15, 2000). O mito é local privilegiado dos arquétipos:

O significado do termo "archetypus" fica sem dúvida mais claro quando se relaciona com o mito, o ensinamento esotérico e o conto de fada. [...] O homem primitivo não se interessa pelas explicações objetivas do óbvio, mas, por outro lado, tem uma necessidade imperativa, ou melhor, a sua alma inconsciente é impelida irresistivelmente a assimilar toda experiência externa sensorial a acontecimentos anímicos. Para o primitivo não basta ver o Sol nascer e declinar; esta observação exterior deve corresponder - para ele - a um acontecimento anímico, isto é, o Sol deve representar em sua trajetória o destino de um deus ou herói que, no fundo, habita unicamente a alma do homem (JUNG, 2000, p. 17-18).

O herói permanece no inconsciente coletivo da humanidade. O super-herói é uma manifestação do arquétipo do herói na alma humana. Viana (2003) apropria-se do conceito de Jung e Erich Fromm 
(que utiliza a expressão Inconsciente Social) para pensar como o super-herói preenche a necessidade de heroísmo do ser humano.

O inconsciente coletivo, do nosso ponto de vista, é o conjunto de necessidades/potencialidades reprimidas em todos os indivíduos que formam uma coletividade (grupo, classe etc.). É no mundo da fantasia, dos sonhos, etc., que ele se manifesta mais constantemente. Os sonhos comuns em um grupo social ou na sociedade são geralmente inacessíveis mas a fantasia não.

As aventuras dos super-heróis expressam uma fantasia que é expressão do inconsciente coletivo: o desejo de poder (VIANA, 2003, p.59).

O desejo de poder é o desejo de realização e autorrealização, de tornar reais as potencialidades e alcançar a liberdade tão reprimida pelo sistema. Ao nos projetar no super-herói o desejo do inconsciente coletivo pode ser atingido.

Voar, por exemplo, é um símbolo de liberdade, de superação de limites, e muitos superheróis possuem este poder. Desta forma, a super-aventura é, em parte, manifestação do inconsciente coletivo e é por isso que ela (e não só ela como também os heróis comuns) tem um público tão grande. Revela-se aí, o potencial emancipador das aventuras dos super-heróis ao manifestar o desejo reprimido de liberdade (VIANA, 2003, p. 59-60).

Com a ascensão dos super-heróis no cinema e nas séries de TV, nos serviços de streaming e nos games esse público cresceu. Essas diferentes linguagens potencializaram ainda mais a possibilidade de transcendência do público infanto-juvenil. Os filmes de super-heróis da Marvel Comics Pantera Negra (2018) e Vingadores Ultimato (2019) tiveram grande repercussão no Brasil e no Mundo, não só pelo sucesso de bilheteria, mas pela manifestação dos jovens no cotidiano. Após analisar uma comunidade de fãs do filme Pantera Negra em uma rede social, YUNES (2018) conclui

Logo, observa-se aqui que as comunidades de fãs e os meios online/digitais podem ir além da simples geração de entretenimento e de diversão. Ao contrário de serem apenas para isto, são espaços de ação ativista que pode gerar reflexões e discussões a respeito de temáticas sociais e culturais do mundo moderno. Desta forma, a liberdade de expressão nestas comunidades online deve ser cada vez mais utilizada a favor de temáticas que busquem reflexões positivas a favor de uma educação positiva, e não para a disseminação de atos de violência, racismo e preconceito (YUNES, 2018, p. 81).

Essa é uma das formas de emancipação nutridas pelos super heróis, mas há outras: Weschenfelder, Fradkin, e Yunes (2017, p. 4), no artigo "Super-heróis como Recursos para Promoção de Resiliência em Crianças e Adolescentes", constatam que "muitos dos super-heróis foram submetidos a múltiplas adversidades com grande similitude às lutas e sofrimentos de crianças e adolescentes de diferentes culturas", e que podem promover resiliência, principalmente em crianças e adolescentes em grupos de risco. O artigo provoca a necessidade de mais pesquisa e reflexão sobre a temática. Os superheróis podem servir de modelo lúdico de superação psicológica para crianças e adolescentes via inconsciente coletivo. O Homem-Aranha perdeu um familiar querido, sofria bullying na escola e tinha problemas financeiros, a maioria dos X-Men sofre preconceito por ser mutante, Demolidor perdeu os pais e a visão, etc. O contato com esses super-heróis pode afetar positivamente a criança e o adolescente 
em situação de sofrimento e risco social por saber que até os super-heróis sofrem e que eles superaram ou aprenderam a conviver com suas dores.

Além do inconsciente coletivo, Viana(2003) discute a questão da ideologia (axiologia) ${ }^{1}$ e os superheróis. Após constatar certas ideologias e refutar outras análises ideológicas equivocadas, conclui

Por último, podemos dizer que a preocupação com o caráter axiológico da superaventura e das histórias em quadrinhos em geral é legítima quando nos dedicamos a pesquisar tal fenômeno social; porém, todas as formas de manifestações culturais que são de ampla circulação (e que são transmitidas através de empresas oligopolistas de meios de comunicação de massas) são axiológicas e por isso a análise da super-aventura deve ir além da constatação óbvia do seu caráter axiológico. Deve desvendar seu processo de formação, suas características e o que mais existe no seu interior (VIANA, 2003, p. 57).

É preciso analisar criticamente as superaventuras lendo suas histórias em quadrinhos, conhecer a linguagem dos quadrinhos, a editora e os autores dos quadrinhos e suas possíveis intenções e interesses. As superaventuras tem uma estrutura própria (como o fato de não haver revoluções que acabam com as desigualdades sociais presentes nas superaventuras) que não deve ser confundida com questões ideológicas.

Tomar esses cuidados não significa esquecer o caráter ideológico (axiológico) dos super-heróis. Há sim valores impregnados nas histórias em quadrinhos que podem influenciar crianças e adolescentes, mas é preciso considerar:

O aspecto "ideológico", sem dúvida, exerce influência sobre os leitores, mas em grau muito menor do que se pensa, pois a atenção do leitor fica mais presa não nos detalhes da narrativa que expressam o seu caráter axiológico e sim nos aspectos fantásticos da história (os combates, a luta pelo poder, os tipos de poderes, os mundos estranhos e maravilhosos, etc.) (VIANA, 2003, p. 61).

As crianças e jovens leitores antes de perceberem o Capitão América nacionalista e defensor dos interesses do imperialismo norte-americano, veem o super-herói forte e ágil que luta contra seus inimigos. Personagens arquetípicos como Superman, Batman e Mulher Maravilha, com sua força mítica, penetram no inconsciente coletivo de crianças e adolescentes fazendo a alma brincar diante de seu mundo, muitas vezes sofridos. Em síntese,

\footnotetext{
${ }^{1}$ Para clarear os conceitos transcrevo na íntegra a nota de rodapé publicada pelo autor "Utilizaremos as expressões ideologia e ideológico em dois sentidos. Um é o utilizado por alguns dos "críticos" das histórias em quadrinhos e tem o significado de uma concepção valorativa. Porém, numa perspectiva dialética, toda forma de consciência é valorativa. Desta forma, não há sentido em acusar algo de ser valorativo, pois tudo é valorativo. Quando se acusa as histórias em quadrinhos de serem valorativas o que se quer dizer na verdade é que elas possuem outros valores, que não os mesmos dos seus críticos. O que alguns querem dizer, neste caso, é, na verdade, "axiologia" e "axiológico". Entendemos por axiologia o padrão dominante de valores em nossa sociedade, os valores burgueses (cf. VIANA, Nildo. A Questão dos Valores. Revista Cultura \& Liberdade. Ano 2, n. 2, abril de 2002). Quando utilizarmos os termos ideológico e ideologia neste sentido usaremos aspas para demarcar a diferença desta concepção com a nossa, mas na maioria dos casos substituiremos estas expressões por axiologia e axiológico. Para nós, ideologia é uma falsa consciência da realidade elaborada de forma sistemática (que, sem dúvida, carrega valores, que são correspondentes aos interesses da classe dominante). Sobre ideologia, cf. MARX, Karl \& ENGELS, Friedrich. A Ideologia Alemã (Feuerbach). 8a edição, São Paulo, Hucitec, 1990.” (VIANA, 2003, p. 50).
} 
O mundo dos super-heróis tem, portanto, duas faces: a axiologia (com seu caráter conservador) e a do inconsciente coletivo (com seu caráter contestador). Essa dupla face dos super-heróis revela que o objetivo consciente dos criadores das histórias é determinado pelos valores dominantes e em certos períodos históricos isto se torna mais forte ainda. Entretanto, ao dar vida à história, escapa-lhes o seu domínio total e quando a fantasia se manifesta, o inconsciente coletivo também aparece (VIANA, 2003, p. 61).

Sob influência da ideologia (axiológica) e do inconsciente coletivo, cria-se um universo moral dos super-heróis. Os quadrinhos, principalmente os de super heróis, na década de 50, sofreram a perseguição de Fredric Wertham ${ }^{2}$ e dos defensores da moral e dos bons costumes, que levou a um Comic Code Authority para garantir que os quadrinhos não ameaçassem a integridade moral e religiosa (na perspectiva conservadora). $\mathrm{Na}$ atualidade, há personagens, os anti-heróis que convivem com os super-heróis "escoteiros", de moral "exemplar". O maniqueísmo é cada vez mais superado, o bem e o mal está no super-herói e está no super-vilão. O super-herói pode nos fazer pensar no que é certo ou errado, pode nos colocar diante de dilemas morais.

Gelson Weschenfelder (2011) analisa os “Aspectos educativos das histórias em quadrinhos de super-heróis e sua importância na formação da consciência moral, na perspectiva da ética aristotélica das virtudes" e mostra como Batman, Homem Aranha, X-Men e Super-Homem detém certas virtudes aristotélicas.

Batman $^{3}$ é o herói mascarado que, quando criança, testemunha o assassinato de seus pais e utiliza todos os recursos - financeiros e aperfeiçoamento de suas qualidades - para fazer justiça combatendo o crime em Gotham City. Batman é um homem virtuoso aristotélico, ao lutar em prol de sua cidade entra em consonância com o pensamento de Aristóteles da realização do homem na pólis, Batman segue o exemplo de virtude que é seu pai e sabe o momento certo de agir e como agir (justa medida). Para Aristóteles, a tensão entre razão e emoção existe, mas "[n]aquele que tem o autocontrole, é a razão que vence. É o caso de Batman, exemplificado no fato de não matar o vilão Coringa, pois sabe que tal ato o tornaria igual a ele. Sendo assim ele já não poderia se igualar ao exemplo de seu pai” (WESCHENFELDER, 2011, p.58).

\footnotetext{
2 Dr. Fredric Wertham, nascido Friedrich Ignatz Wertheimer (20 de março de 1895 - 18 de novembro de 1981) foi um psiquiatra, pesquisador e escritor alemão, Whertam se mudou pros Estados Unidos, onde se tornou professor, protestava contra os efeitos supostamente nocivos de imagens violentas na mídia de massa e revistas em quadrinhos sobre o desenvolvimento das crianças. A partir de 1948, ele se juntou a uma campanha contra as revistas em quadrinhos. Em especial, uma entrevista publicada na revista semanal Collier's Weekly intitulada Horror in the Nursery e o artigo The Psychopathology of Comic Books na revista científica The American Journal of Psychotherapy. Wertham não está sozinho em criticar os quadrinhos, mas suas qualificações científicas e perito citado pelas autoridades em muitos casos judiciais tornam particularmente convincente. Seu livro mais conhecido foi Seduction of the Innocent (1954), que sugeriu que os quadrinhos eram perigosos para as crianças. As críticas de Wertham ajudaram a desencadear um inquérito no Congresso dos Estados Unidos sobre a indústria dos quadrinhos e a criação do Comics Code Authority, um código que regulava a publicação dos quadrinhos através do fornecimento de um selo de permissão para a publicação. Disponível em https://pt.wikipedia.org/wiki/Fredric Wertham acesso em 01/09/2020.

${ }^{3}$ Batman (DC Comics), criado em 1939 pelo escritor Bill Finger e pelo artista Bob Kane.
} 
Batman treina para equilibrar corpo e alma e manter-se como o homem da justa medida aristotélica.

Peter Parker, ao ser picado por uma aranha radioativa, adquire habilidades espetaculares e se torna o Homem Aranha ${ }^{4}$, combatendo o crime em Nova Iorque. Suas qualidades altruístas o aproximam da ética de Aristóteles:

Na perspectiva aristotélica, Peter Parker se torna virtuoso no momento que aceitou utilizar seus dons em prol dos cidadãos novaiorquinos, porque isso o levou a realizar plenamente o seu potencial, em outros termos, a atingir a excelência moral (WESCHENFELDER, 2011, p. 67)

Nem a sua vida problemática o impediu de ajudar as pessoas. De fato, o Homem Aranha compreendeu que "com grandes poderes vem grandes responsabilidades" e aprendeu a fazer as escolhas corretas.

Os X-Men ${ }^{5}$, o grupo de mutantes rejeitados pela maioria da humanidade e guiados pelo professor Charles Xavier também demonstram características da ética aristotélica.

Pelos ensinamentos do Professor X os Mutantes tomam consciência de que não podem desistir, pois o futuro dos mutantes depende somente do resultado da luta deles, vencer o egoísmo individual e lutar por uma sociedade tolerante. E eles precisam colocar em prática o que aprenderam no Instituto Xavier, um caminho para o ‘bem’ e a paz. Assim, por meio da educação, estes super-heróis mutantes apostam nos valores que o mestre lhes propôs, e têm uma motivação interior para fazer o que é correto e bom, um impulso interno, emocional ou psicológico, que pode proporcionar um motivo para resistir à tentação de se voltar para os próprios interesses. Buscar um modelo de caráter, ouvir e seguir os seus passos, treinar seus dons e usá-los em prol dos outros na construção da tolerância entre duas raças (mutante e humana), é o caminho aristotélico para o bem supremo, finalidade do homem, humano ou mutante (WESCHENFELDER, 2011, p. 79).

O valor do respeito à diversidade e combate ao preconceito presente nas superaventuras dos X-

Men demonstram que o ideal de Charles Xavier serve de exemplo para os demais mutantes que o seguem.

O super-herói mais famoso da cultura pop, Super-Homem, é também um dos que mais representa a virtude aristotélica.

Super-Homem quando vive em total autenticidade, aceitando com naturalidade seus dons e aplicando estes a serviço dos outros, ele vive em excelência. Ao mesmo modo, Aristóteles, em sua obra Ética a Nicômaco, que estudava a felicidade como a finalidade do homem, começou a observar o que é viver em excelência, enunciando assim: 'se a felicidade consiste na atividade de acordo com a virtude, é razoável que seja atividade de acordo com a virtude maior (excelência), e esta será a virtude da melhor parte de nós' (ARISTÓTELES, 2007. X, 1177 a1, 10-14). De certo modo, Super-Homem, o personagem mais conhecido das histórias em quadrinhos de superaventuras, vivencia

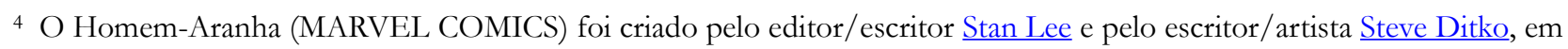
1962.

${ }^{5}$ X-Men (MARVEL COMICS) foram criados por Stan Lee e Jack Kirby, em 1963, e era formado inicialmente pelo Professor $\mathrm{X}$, fundador da equipe, Ciclope, Fera, Homem de Gelo, Anjo e Garota Marvel (Jean Grey).
} 
em suas aventuras, a finalidade do homem para Aristóteles, a felicidade (WESCHENFELDER, 2011, p.86).

Super-Homem 6 é o "bom escoteiro", o arquétipo de virtude. Nele a justiça e o bem se concretizam. Clark Kent/Kal-el teve exemplo de virtude de seus pais terrenos e se tornou exemplo para a humanidade.

A moralidade presente nas histórias de super-heróis muda constantemente, de acordo com o escritor e a editora ou a produtora no caso de outras mídias ou mesmo para outros tipos de público. Por isso os super-heróis de Watchmen ${ }^{7}$, The Boys ${ }^{8}$ e outros que extrapolaram o convencional da moralidade vigente aparecem nas Histórias em quadrinhos e em outras mídias.

O fato é que o mito do super-herói se articula com o Inconsciente coletivo, com a ideologia (axiologia) e com a moralidade e essa articulação pode ser positiva para práticas educativas de humanidades.

\section{Reflexões da relação super-heróis e educação}

Os super-heróis como foram apresentados podem dar contribuições para o ensino de humanidades.

Que superpoderes há em cada um de nós? Como utilizamos esses superpoderes? Para quem utilizamos esses superpoderes? O que é um superpoder? Além do superpoder, o que precisamos para nos tornar super-heróis?

Essas e outras perguntas podem ser feitas pelo educador para proporcionar uma experiência de aprendizado que favoreça a emancipação intelectual, emocional, social e psíquica de nossos estudantes. O contato do educador com o super-herói pode proporcionar experiências que promovam o movimento dessas perguntas. Entrar em contato com o super-herói significa abrir-se para a fantasia e deixar o arquétipo do herói perpassar sua vida. Ler quadrinhos, assistir filmes e séries é um primeiro contato.

\footnotetext{
${ }^{6}$ Superman ou Super-Homem (DC COMICS) Criado por Joe Shuster e Jerry Siegel em 1938

${ }^{7}$ Watchmen é uma série limitada de história em quadrinhos escrita por Alan Moore e ilustrada por Dave Gibbons, publicada originalmente em doze edições mensais pela editora estadunidense DC Comics entre 1986 e 1987 (...)A trama de Watchmen é situada nos EUA de 1985, um país no qual aventureiros fantasiados seriam realidade. O país estaria vivendo um momento delicado no contexto da Guerra Fria e em via de declarar uma guerra nuclear contra a União Soviética. A mesma trama envolve os episódios vividos por um grupo de super-heróis do passado e do presente e os eventos que circundam o misterioso assassinato de um deles. Watchmen retrata os super-heróis como indivíduos verossímeis, que enfrentam problemas éticos e psicológicos, lutando contra neuroses e defeitos, e procurando evitar os arquétipos e super-poderes tipicamente encontrados nas figuras tradicionais do gênero. Isto, combinado com sua adaptação inovadora de técnicas cinematográficas, o uso frequente de simbolismo, diálogos em camadas e metaficção, influenciaram tanto o mundo do cinema quanto dos quadrinhos. Disponível em https://pt.wikipedia.org/wiki/Watchmen acesso em 20/08/2020

8 The Boys (Dynamite Entertainment) é uma série de revistas em quadrinhos americana criada por Garth Ennis e Darick Robertson (2006). The Boys narra uma série de eventos ocorridos entre 2006 e 2008 num universo ficcional onde superheróis existem, mas em sua grande parte tiveram seus valores morais corrompidos pela fama e celebridade que alcançaram, e não raro se comportam de forma irresponsável. Por isso, um esquadrão de agentes da $\underline{\text { CIA, }}$ conhecidos informalmente como "The Boys", é responsável por monitorar as atividades da comunidade de seres super-poderosos. A história se foca em Hugh "Wee Hughie" Campbell, que após sua namorada ter sido morta durante um conflito entre heróis e vilões, passa a odiar os heróis. Hugh é convidado por Billy Butcher, líder dos The Boys a se juntar ao grupo e monitorar os heróis. Disponível em https://pt.wikipedia.org/wiki/The Boys (revista em quadrinhos) acesso em 20/08/2020.
} 
Dialogar com crianças e adolescentes como aprendiz é outro. A partir daí novas perguntas surgirão e o movimento pedagógico terá um rumo.

Uma das questões discutidas acima é a questão do inconsciente coletivo e sua relação com o super-herói. O mito do super-herói que perpassa o inconsciente coletivo e conquista crianças e adolescentes pode ser utilizado em qualquer aula de humanidades.

Ler uma história em quadrinhos como obra de arte sem a preocupação de transmitir conhecimento, já ensina! Apresentar histórias de super-heróis para crianças e adolescentes já é um ato educativo. Quando o educador seleciona um material adequado para cada faixa etária, com estética e textualidade de qualidade e o expõe didaticamente, é possível criar um "clima” favorável ao aprender pela sensibilidade, ao aprendizado literário e mítico. A ludicidade de uma superaventura já traz uma série de aprendizados, já que toca no inconsciente coletivo despertando o super-herói em cada um e

[a]lém de estimular as crianças e adolescentes a encarar seus medos e enfrentar desafios, estes também são impulsionados a proteger os mais fracos, lutar por ideais e combater o inaceitável. Mais do que exemplos de força e coragem, estes personagens são modelos morais (WESCHENFELDER, 2019, p. 20)

Logicamente que deve-se construir um processo pedagógico após essa apresentação para atingir outros objetivos criados pelo professor, como discutir ciência e tecnologia presente em muitas superaventuras e o período histórico em que ela acontece.

Pode-se promover discussão sobre como esses super-heróis, tão humanos, superam seus problemas e dificuldades. A atitude é que os tornam heróis, mais que os superpoderes eles precisam de atitudes sábias. Os estudantes têm superpoderes para aprender, mas certas atitudes ou não tomar atitudes não contribuem para seu aprendizado. O educador deve proporcionar o aprendizado de atitudes. Mas como ensinar atitudes? Não há fórmulas prontas e acabadas, mas há histórias de super-heróis que demonstram isso.

No primeiro filme do Homem-Aranha, de 2002, dirigido por Sam Raimi, há a cena em que o Duende Verde sequestra Mary Jane, amada de Peter Parker e um bonde com crianças. O inimigo do Homem Aranha o desafia a escolher salvar Mary Jane ou o bonde com crianças e lança ambos da ponte. A atitude do herói aracnídeo foi utilizar sua inteligência e seus superpoderes para salvar todos. O superherói foi colocado diante de um dilema e teve que decidir em questão de segundos. O Homem Aranha foi resiliente diante da angústia moral a que foi submetido e decidiu. Um exemplo de provocação a ser realizado com alunos.

A questão da atitude se liga à moralidade do super-herói e a axiologia (ideologia). A atitude é a postura diante de uma situação que leva o sujeito a ação. O agir moral é carregado de valores (axiologia). Algumas decisões de super-heróis podem estar fortemente vinculadas a uma concepção de sociedade e do que é certo e errado. Eles podem cometer erros, como seres humanos e é preciso lançar questionamento sobre a ação desse super-herói, mesmo quando parecer correto. A atitude desse super- 
herói foi correta? O "correto" dentro desse contexto pode ser relativizado? A atitude desse super-herói representa que tipo de sociedade ou grupo social?

Deve-se levar em consideração que a atitude heroica pode carregar ideologias diversas de um determinado grupo da sociedade. O estudante pode desvelar as ideologias presentes na superaventura, com as ferramentas da área de humanas, estabelecendo a relação da história do super-herói com a realidade e a forma como os elementos textuais são apresentados. Por que essa superaventura foi escolhida para essa aula? Que perguntas podem ser elaboradas sobre a história? Por que os personagens têm esses valores? A ação dos personagens tem um sentido simbólico ou corresponde com a realidade? O que está para além da aparência imediata? Você concorda com a ideia principal dessa superaventura? Que investigações podem ser feitas para descobrir o que há por trás dessa superaventura?

\section{Conclusão}

Há muito que explorar no mito do super-herói e toda influência que eles exercem nos estudantes da educação básica. As reflexões expostas aqui se tornam um elemento a mais para se pensar o porque e o como, mas também o que e para que.

Por que esses super-heróis influenciam as crianças e adolescentes? Por que super-heróis na educação? Por que aprender/ensinar com e pelos super-heróis?

Como aprender/ensinar com super-heróis? Como a ideologia dos super-heróis pode afetar estudantes, professores e a sociedade? Como mergulhar na fantasia das superaventuras e absorve-las no inconsciente coletivo para aprender/ensinar? Como a atitude e ações dos super-heróis pode contribuir com o pensar ético do estudante?

O que ensinar no ensino/aprendizado com/pelos super-heróis? O que pode um estudante diante de um processo educativo com super-heróis? O que é o super-herói?

Para que ensinar/aprender com super-heróis? Para que tornar "superpoderes" presentes na vida dos alunos(as)?

O super-herói é uma potência presente na escola, na vida de estudantes, é um mito capaz de mexer com arquétipos mais profundos da existência humana e, portanto, apta a participar da educação de crianças, de jovens e, por que não, de adultos. $\mathrm{O}(\mathrm{A})$ estudante pode aprender a lidar com sua existencialidade (inconsciente coletivo), com a sociedade e sua ideologia (axiologia) e suas ações morais.

Se o(a) educador(a) se apropriar de seus superpoderes pedagógicos, que inclui as ferramentas necessárias para contribuir com a emancipação do estudante, a crítica aos mecanismos da indústria cultural de massa presentes nas superaventuras e as ideologias presentes ali, os instrumentos didáticos necessários e o reconhecimento da potência do super-herói é possível tornar o espaço escolar, um espaço de promoção da liberdade e de transcendência humana. 


\section{REFERÊNCIAS}

CAMPBELL, Joseph. O herói de mil faces. 10. ed. São Paulo:Cultrix/Pensamento, 1997

JUNG, C. G. Os arquétipos e o inconsciente coletivo. Petrópolis, RJ: Vozes, 2000. (Obras completas de C. G. Jung, v.9/1).

PANTERA NEGRA. Direção: Ryan Coogler, 2018.(135 min)

VIANA, Nildo. Axiologia e Inconsciente Coletivo no Mundo dos Super-Heróis. Revista Eletrônica Espaço Acadêmico, Maringá/PR., v. 29, 2003.

VINGADORES - ULTIMATO. Direção A. Russo e J. Russo. Marvel Studios. 2019(181 min)

WESCHENFELDER, Gelson Vanderlei; FRADKIN, Chris e YUNES, Maria Angela Mattar. Superheróis como Recursos para Promoção de Resiliência em Crianças e Adolescentes. Psic.: Teor. $e$ Pesq. [online]. 2017, vol.33, e 33425 Disponível em https://www.scielo.br/scielo.php?pid=S0102$37722017000100423 \&$ script $=$ sci_abstract\&tlng=pt acesso em 30/08/2020.

WESCHENFELDER, Gelson Vanderlei; FRADKIN, Chris e YUNES, Maria Angela Mattar. Aspectos educativos das histórias em quadrinhos de Super-Heróis e sua importância na formação da consciência moral, na perspectiva da ética Aristotélica das Virtudes. - (Mestrado em Educação) Centro Universitário La Salle - UNILASALLE - Canoas, 2011 - Disponível em: http://biblioteca.unilasalle.edu.br/ docs online/tcc/mestrado/educacao/2011/ gvweschenfelder. pdf Acesso em: 08/10/2014.

WESCHENFELDER, Gelson Vanderlei; FRADKIN, Chris e YUNES, Maria Angela Mattar. Além da superaventura: quadrinhos em ambiente escolar. Cadernos de Estudos e Pesquisa na Educação Básica, Recife, v. 5, 2019. ISSN 2447-6943. Disponível em https://periodicos.ufpe.br/revistas/cadernoscap/article/view/243374 acesso em 16/11/2020 YUNES, Mariana Mattar. A representação de heroísmo negro e expressões de impacto no filme Pantera Negra: análise de conteúdo em uma comunidade de fãs. Diálogo, n. 39, p. 67-82, 2018.Disponível em https://revistas.unilasalle.edu.br/index.php/Dialogo/article/view/4931 acesso em 16/11/2020. 